\title{
Energy drink consumption pattern and the effect of consumption on university students' blood pressure and heart rate
}

\author{
K. Nagy \\ e-mail: nagykinga9@gmail.com
}

B. Dániel

e-mail: Diablo1@gmail.hu

\author{
A. Csomós \\ e-mail: csomosadel@gmail.com
}

Gy. Mara*

e-mail: maragyongyver@uni.sapientia.ro

Sapientia Hungarian University of Transylvania (Cluj-Napoca, Romania),

Faculty of Economics, Socio-Human Sciences and Engineering, Department of Bioengineering, RO-530104 Miercurea Ciuc, 1 Libertăţii Sq.

*corresponding author

\begin{abstract}
Energy drink (ED) consumption, even mixed with alcohol, is popular among adolescents and young adults. The side effects of ED are attributed to their active ingredients and their cumulated effect. A cross-sectional study to identify university students' ED consumption habit was realized. A small sample size $(\mathrm{n}=10)$ experiment examining the effect of ED consumption on arterial blood pressure and heart rate was carried out.

From the total number of 240 interviewed students, $87.1 \%$ consumed ED at least once, and one third of them did so on a monthly basis. Students consume energy drinks mainly for its taste, very rarely for studying. Differences in consumption place preferences were observed between sexes, females preferring bars, while males the dormitory. We have demonstrated the increase of systolic blood pressure (SBP) for one type of energy drink in young and healthy volunteer students. Other changes in blood pressure and heart rate were not observed.
\end{abstract}

Keywords and phrases: caffeinated drinks, questionnaire survey, volunteer students, cardiovascular parameters 


\section{Introduction}

Energy drinks are a relatively new product category on the food market. The first energy drink was launched in Japan in 1960 followed by the appearance of Red Bull on the European market in 1987 (Zucconi et al., 2013). A unanimous definition is still missing. Such drink category includes beverages that contain various ingredients, including: caffeine, herbal extracts, B vitamins, amino acids (taurine), amino acid derivatives (carnitine), sugar derivatives (glucuronolactone), and sugars or sweeteners (Malinauskas et al., 2007; Zucconi et al., 2013). Energy drinks may contain from $70 \mathrm{mg}$ to $400 \mathrm{mg} / \mathrm{L}$ caffeine (Zucconi et al., 2013). Energy drinks are most frequently used as energizers, stimulants, and performance enhancers. They should not be confused with isotonic beverages and sports drinks, which are considered functional foods. Energy drinks are not recommended to be consumed during physical activities, such as exercising or making physical effort, because the fluid loss and sweating can lead to an intense dehydrated condition and sodium imbalance (Alsunni, 2015).

There is a growing demand of energy drinks on a global scale due to the increased consumption in the past two decades mainly among adolescents and young adults. The global sale was 14.68 billion litres in 2018. The major market of energy drinks is North America followed by Asia-Pacific and Europe. On the global market, there are hundreds of different brands with major players such as Red Bull, Monster Beverages, and Rockstar Inc. (Mordor Intelligence, 2019).

Major companies have a very effective advertising, involving movie stars and famous people influencing mainly the vulnerable age-groups such as adolescents and young adults. They are the main targets of the marketing slogans, easily impressionable by the allocated effects to these drinks, such as boosting performance, feeling more energetic, reducing fatigue, helping to stay awake, etc. The susceptibility of adolescents and young adults are confirmed by the literature data. According to a European survey covering 16 Member States including Romania and Hungary, 30\% of adults (18-68 years) and 68\% of adolescents (10-18 years) interviewed were energy drink consumers (Zucconi et al., 2013).

The side effects of energy drinks are attributed to their active ingredients such as caffeine, taurine, and glucuronolactone and their cumulated effect with other substances (Itany et al., 2014). Therefore, it is required on the European market that beverages containing at least $150 \mathrm{mg} / \mathrm{L}$ caffeine to be labelled as "High caffeine content" (Directive 2002/67/EC). Caffeine has numerous 
effects on the organism such as vasoconstriction due to antagonized adenosine receptors, increased basal metabolic rate caused by the upregulated circulation of cathecolamines, and water and sodium secretion (Persad, 2011; Oprea et al., 2019). Taurine is a normal constituent of human cells; it was associated with several physiological functions such as neuro- and cellular membrane modulation or the modulation of $\mathrm{Ca}^{2+}$ levels (Oprea et al., 2019). Energy drink consumption in excess may cause cardiovascular, neurological, psychological, gastrointestinal, metabolic, and renal diseases (Lee et al., 2005; Bichler et al., 2006; Alsunni, 2015; Shah et al., 2016; Utter et al., 2017).

Young adults tend to mix energy drinks with alcohol. In the USA, the prevalence of alcohol mixing with energy drink (AMED) varied between 8.1 and $64.7 \%$ and in Australia between 21.1 and $77 \%$ (Verster et al., 2018). In an expanded European study, co-consumption with alcohol showed similar values: $56 \%$ among adults versus 53\% among adolescents (Zucconi et al., 2013). The potential risks of AMED are the following: increased total alcohol intake, masked intoxication effects and increased risk-taking behaviour (McKetin et al., 2015; Verster et al., 2018; Benson et al., 2019).

The aim of the study was to identify energy drink consumption habits and their effect on arterial blood pressure and heart rate in the context of possible risk of cardiovascular diseases among university students of Sapientia Hungarian University of Transylvania.

\section{Materials and methods}

Questionnaire survey

A cross-sectional study was conducted among the students of Sapientia Hungarian University of Transylvania (Cluj-Napoca), Faculty of Economics, SocioHuman Sciences and Engineering, Miercurea Ciuc. The data were collected online via Google anonymous questionnaire during the spring of 2019. The questionnaire consisted of 19 questions on students' socio-demographic characteristics, habits, energy-drink-related habits, and health-impairment-related knowledge. The questionnaire was filled by $240(27.97 \%)$ students from the 858 total active students of the faculty in the academic year 2018-2019.

\section{Subjects}

The energy drink consumption study was set up with a group of twelve volunteer students recruited from Sapientia Hungarian University of Transyl- 
vania, Faculty of Economics, Socio-Human Sciences and Engineering, Miercurea Ciuc. Exclusion criteria were: cardiovascular diseases and certain kind of chronic diseases. Before starting the experiment, volunteers received verbal and written instructions, and they signed a statement of consent on study participation and on using their data anonymously for the purposes of our study. Before the experiment, participants were asked not to consume any caffeine-containing drinks for $12 \mathrm{hrs}$ before the study. After the experiment, we managed to collect full data on 10 students.

Study protocol

For the experiment, three popular energy drinks and a control drink was purchased in a shop. The ingredients of these drinks are shown in Table 1.

Each volunteer consumed $250 \mathrm{~mL}$ drink (three types of energy drink and one control drink) on experimental days. Arterial blood pressure (systolic SBP and diastolic DBP) and heart rate (HR) were measured before consuming and 20 min after consuming the drinks. Arterial blood pressure and heart rate were measured with a Beurer Blood Pressure Monitor. All measurements were performed on the arm of the non-dominant hand and were repeated three times.

Table 1: Ingredients in $100 \mathrm{~g}$ drink used during the experiment

\begin{tabular}{lcccc}
\hline Ingredient & Control drink & Drink 1 & Drink 2 & Drink 3 \\
\hline Caffeine & - & $29 \mathrm{mg}$ & $32 \mathrm{mg}$ & $33 \mathrm{mg}$ \\
Taurine & - & $400 \mathrm{mg}$ & $400 \mathrm{mg}$ & $250 \mathrm{mg}$ \\
Sugar & $9.09 \mathrm{~g}$ & $10.22 \mathrm{~g}$ & $11 \mathrm{~g}$ & $10.93 \mathrm{~g}$ \\
Ginseng extract & - & - & - & $40 \mathrm{mg}$ \\
Niacin & - & $9.82 \mathrm{mg}$ & $8 \mathrm{mg}$ & $10.16 \mathrm{mg}$ \\
Vitamin B-6 & - & $2.16 \mathrm{mg}$ & $0.8 \mathrm{mg}$ & $1.01 \mathrm{mg}$ \\
Vitamin B-12 & - & $1.97 \mathrm{mg}$ & $0.2 \mu \mathrm{g}$ & $2.57 \mathrm{mg}$ \\
Pantothenic acid & - & - & $2.0 \mathrm{mg}$ & - \\
\hline
\end{tabular}

\section{Statistical analysis}

All the data were processed in Microsoft Excel by calculating the mean and standard deviation. To interpret the results of two samples, paired t-test and chi-square test were used, performed with Past3 and SPSS (Version 22) software. P-values lower than 0.05 were considered as significant. 


\section{Results and discussions}

Socio-demographic characteristics, participants' habits and energy drink consumption pattern

The questionnaire was filled by a total number of $240(27.97 \%$ of the totality of faculty's students) students of Sapientia Hungarian University of Transylvania. Students' socio-demographic characteristics are presented in Table 2. Of the participants, $159(66.2 \%)$ were females and $81(33.8 \%)$ were males. Participants included in data analysis ranged from 18 to 30 years of age. The age distribution was the following: 45 students (18.8\%) were under 20 years, 157 students (65.4\%) were between 20 and 24 years, and 38 students $(15.8 \%)$ were above 24 years. Regarding accommodation, the participants shared residency with parents, lived in dormitories or in lodgings approximately in the same proportion $(30 \%, 35.4 \%, 29.2 \%)$, whereas $5.4 \%$ commuted from home to university. Concerning the parents' educational level, $58.8 \%$ of the mothers and $66.3 \%$ of the fathers were high-school graduated.

Table 2: Participants' socio-demographic characteristics

\begin{tabular}{|c|c|c|}
\hline Characteristics & No. $(n=240)$ & Percentage \\
\hline \multicolumn{3}{|l|}{ Gender } \\
\hline Male & 81 & $33.8 \%$ \\
\hline Female & 159 & $66.3 \%$ \\
\hline \multicolumn{3}{|l|}{ Age-groups } \\
\hline$<20$ & 45 & $18.8 \%$ \\
\hline $20-24$ & 157 & $65.4 \%$ \\
\hline$>24$ & 38 & $15.8 \%$ \\
\hline \multicolumn{3}{|l|}{ Accommodation } \\
\hline At home with the family & 72 & $30 \%$ \\
\hline Live in dormitory & 85 & $35.4 \%$ \\
\hline Live in lodgings & 70 & $29.2 \%$ \\
\hline Commute & 13 & $5.4 \%$ \\
\hline \multicolumn{3}{|l|}{ Mother's educational level } \\
\hline Primary-school graduate & 14 & $5.8 \%$ \\
\hline High-school graduate & 141 & $58.8 \%$ \\
\hline $\begin{array}{l}\text { College/university graduate } \\
\text { (including postgraduate degrees) }\end{array}$ & 85 & $35.4 \%$ \\
\hline \multicolumn{3}{|l|}{ Father's educational level } \\
\hline Primary-school graduate & 11 & $4.6 \%$ \\
\hline High-school graduate & 159 & $66.3 \%$ \\
\hline $\begin{array}{l}\text { College/university graduate } \\
\text { (including postgraduate degrees) }\end{array}$ & 70 & $29.1 \%$ \\
\hline
\end{tabular}


Table 3 presents students' cigarette, alcohol, and energy drink consumption patterns. More than half of the students (58.3\%) are non-smokers, and $41.7 \%$ are smokers. $88.3 \%$ of the students reported that they consumed alcohol with variable frequency, while $11.7 \%$ did not consume any alcohol. The majority of the students $(87.1 \%)$ consumed at least once, whereas $12.9 \%$ never tried it out. Of those who never tried it, $87.1 \%$ considered energy drink unhealthy. A similarly high proportion of students that consumed at least once energy drink was observed in Hungary (95.3\%; Dojcsákné Kiss-Tóth \& Kiss-Tóth, 2018), Italy (75.8\%; Vitiello et al., 2016), Lebanon (63.6\%; Itany et al., 2014), and the USA (70.1\%; Pettit \& DeBarr, 2011). A significant difference between our results and those obtained at a Turkish university was observed, where $53.5 \%$ of the interviewed students never tried consuming any energy drinks (Bulut et al., 2014).

Table 3: Participants' habits regarding smoking, alcohol, and energy drink consumption

\begin{tabular}{lcc}
\hline \multicolumn{1}{c}{ Characteristics } & No. $(\mathbf{n}=\mathbf{2 4 0})$ & Percentage \\
\hline Cigarette smoking & 140 & \\
Non-smokers & 100 & $48.3 \%$ \\
Smokers & & \\
Alcohol use & 28 & $11.7 \%$ \\
Not using & 212 & $88.3 \%$ \\
Using & & \\
Energy drink consumption & 209 & $87.1 \%$ \\
Consumed at least once & 31 & $12.9 \%$ \\
Never tried & & \\
Main reason for NOT trying ED & 4 & $12.9 \%$ \\
No particular reason & 27 & $87.1 \%$ \\
Consider unhealthy & & \\
\hline
\end{tabular}

The pattern of energy drink consumption by the faculty students is presented in Table 4. The highest proportion of students consume one energy drink per month $(67 \%), 19.1 \%$ of the surveyed students consume energy drinks on a weekly basis, while $5.8 \%$ of them does it on a daily basis. Other studies report different energy drink consumption frequency from our data: $51 \%$ of USA students consume more than one energy drink per month (Malinauskas et al., 2007), while those from Lebanon consume less than one energy drink per month (Itany et al., 2014). The weekly consumption of energy drinks was 
observed in a similar proportion in Danish (Friis et al., 2014), Italian ( Vitiello et al., 2016), and Hungarian (Dojcsákné Kiss-Tóth \& Kiss-Tóth, 2018) students $(15.8 \%, 15.8 \%, 14.4 \%)$, which correlates with our data.

Table 4: Participants' habits of energy drink consumption

\begin{tabular}{|c|c|c|}
\hline Characteristics & No. $(n=209)$ & Percentage \\
\hline \multicolumn{3}{|c|}{ Frequency of ED consumption $(n=209)$} \\
\hline$>1$ bottle/month & 17 & $8.1 \%$ \\
\hline 1 bottle/month & 140 & $67 \%$ \\
\hline$>1$ bottles/week & 22 & $10.5 \%$ \\
\hline 1 bottle/week & 18 & $8.6 \%$ \\
\hline 1 bottle/day & 6 & $2.9 \%$ \\
\hline$>1$ bottle/day & 6 & $2.9 \%$ \\
\hline \multicolumn{3}{|l|}{ Main reason for consuming EDs } \\
\hline Good taste & 118 & $56.5 \%$ \\
\hline Energy need & 22 & $10.5 \%$ \\
\hline Studying & 8 & $3.8 \%$ \\
\hline To stay awake for hours & 26 & $12.4 \%$ \\
\hline Reduce fatigue & 27 & $12.9 \%$ \\
\hline Other reason & 8 & $3.8 \%$ \\
\hline \multicolumn{3}{|c|}{ Time of first experience with EDs } \\
\hline In primary school & 69 & $33 \%$ \\
\hline In high school & 119 & $56.9 \%$ \\
\hline In college/university & 21 & $10 \%$ \\
\hline \multicolumn{3}{|c|}{ Place of first time for trying $E D$} \\
\hline At home & 39 & $18.7 \%$ \\
\hline Bar & 38 & $18.2 \%$ \\
\hline Coffee shop & 11 & $5.3 \%$ \\
\hline At a party & 20 & $9.6 \%$ \\
\hline Other places & 14 & $6.7 \%$ \\
\hline Not remember & 87 & $41.6 \%$ \\
\hline \multicolumn{3}{|c|}{ Companion when first tried an ED } \\
\hline None & 29 & $13.9 \%$ \\
\hline Friend(s) & 163 & $78 \%$ \\
\hline Family members & 15 & $7.2 \%$ \\
\hline Not remember & 2 & $1 \%$ \\
\hline \multicolumn{3}{|l|}{ Type of preferred ED } \\
\hline Hell & 144 & $71.6 \%$ \\
\hline Red Bull & 37 & $18.4 \%$ \\
\hline Monster & 12 & $6 \%$ \\
\hline Crazy Wolf & 4 & $2 \%$ \\
\hline Burn & 1 & $0.5 \%$ \\
\hline Other & 3 & $1.5 \%$ \\
\hline \multicolumn{3}{|l|}{ Place of consumption } \\
\hline Bar & 81 & $39.1 \%$ \\
\hline At home & 46 & $22.2 \%$ \\
\hline In dormitory & 42 & $20.3 \%$ \\
\hline Coffee shop & 13 & $6.3 \%$ \\
\hline Other & 13 & $6.3 \%$ \\
\hline At university & 7 & $3.4 \%$ \\
\hline At work & 5 & $2.4 \%$ \\
\hline
\end{tabular}


For more than half of the interviewed students (56.5\%), the main reason for consuming energy drinks was their taste. In a Turkish study, 48.3\% (Sema \& Cakir, 2011) while in an Italian study $31 \%$ of the students consumed energy drinks for their taste (Scuri et al., 2018). One eighth of our students consume energy drinks to reduce fatigue (12.9\%) and to stay awake (12.4\%). Similar values (10.3\%) for reducing fatigue were observed in Turkish students (Bulut et al., 2014), whereas the ratio of students consuming energy drinks for staying awake was lower (5\%) in a Turkish study (Sema \& Çakir, 2011) and higher $(33 \%)$ in an Italian study (Scuri et al., 2018). Our data show that one tenth $(10.5 \%)$ of students consume energy drinks to feel more energetic. This reason was mentioned in a higher proportion (15.9\%) among Turkish students (Sema \& Çakir, 2011) and Italian students (32.5-44\%) (Vitiello et al., 2016; Scuri et al., 2018). The smallest proportion of the students (3.8\%) consume energy drinks to boost performance during studying. Similar data $(4 \%)$ were obtained by Sema \& Çakir (2011) among Turkish university students. In other studies, this reason was determining for a higher proportion of students (14\%-28.6\%) (Bulut et al., 2014; Vitiello et al., 2016; Scuri et al., 2018). The most frequent places of consumption are bars $(39.1 \%)$, homes $(22.2 \%)$, and dormitories $(20.3 \%)$. Our data correlates with those obtained at the Turkish university (Sema \& Çakir, 2011).

The first experience with energy drinks was in high school for more than half of the students (56.9\%) in the companion of friends (78\%). At a Turkish university, energy drink consumption took place later in life, as university students (58.9\%), in the companion of friends (59.2\%) (Sema \& Çakir, 2011).

The most popular energy drink brands among the faculty students were Hell (71.6\%) and Red Bull (18.4\%). The popularity of Red Bull was greater in studies from Italy, Turkey, and Lebanon (51.7-73.6\%) (Sema \& Çakir, 2011; Itany et al., 2014; Scuri et al., 2018). The popularity of the Hell energy drink in our region can be explained by the Eastern European (Hungary) origin of the company.

Energy drink consumption frequency differs significantly between males and females, being higher in females for bottle per month and lower for bottle per day consumption (Table 5).

Malinauskas et al. (2007) reported in a study based on American students that significantly more females $(53 \%)$ than males $(42 \%)$ consumed energy drinks. Other studies highlight the difference between sexes in favour of the male gender, which is more exposed to consumption (Pettit \& DeBarr, 2011; Bulut et al., 2014; Friis et al., 2014; Itany et al., 2014; Vitiello et al., 2016). 
Table 5: Frequency of energy drink consumption among energy drink consuming university students

\begin{tabular}{lcccc}
\hline \multicolumn{1}{c}{ Frequency } & \% males & \% females & $\chi^{\mathbf{2}}$ & p (sex) \\
\hline$>1$ bottle/month & 7.7 & 8.4 & 0.03 & 0.85 \\
1 bottle/month & 57.7 & 72.5 & 4.85 & $<0.05$ \\
$>1$ bottle/week & 15.4 & 7.6 & 3.11 & 0.07 \\
1 bottle/week & 9 & 8.4 & 0.02 & 0.88 \\
$>1$ bottle/day & 3.8 & 2.3 & 0.42 & 0.51 \\
1 bottle/day & 6.4 & 0.8 & 5.59 & $<0.05$ \\
\hline
\end{tabular}

$n=78$ males, 131 females, $\chi^{2}(1, N=209)$

Table 6 presents the data on genders regarding the main reason of energy drink consumption. Differences between the sexes were not statistically significant for this issue. The same results were obtained for American students by Malinauskas et al. (2007).

Table 6: Situation of energy drink consumption among energy drink consuming university students

\begin{tabular}{lcccc}
\hline \multicolumn{1}{c}{ Situation } & \% males & \% females & $\chi^{\mathbf{2}}$ & $\mathbf{p ~ ( s e x )}$ \\
\hline To stay awake for hours & 16.7 & 10.7 & 1.55 & 0.21 \\
Good taste & 59 & 55 & 0.32 & 0.57 \\
Energy need & 9 & 11.5 & 0.31 & 0.57 \\
Reduce fatigue & 7.7 & 15.3 & 2.57 & 0.10 \\
Studying & 3.8 & 3.8 & 0.00 & 0.99 \\
\hline
\end{tabular}

$n=78$ males, 131 females, $\chi^{2}(1, N=209)$

Differences between the sexes regarding the preferences for the place of consumption were observed (Table 7), females opting more often to consume energy drinks in bars while males in dormitories. 
Table 7: Place of consumption of energy drinks among energy drink consuming university students

\begin{tabular}{lcccc}
\hline Place of consumption & \% males & \% females & $\chi^{\mathbf{2}}$ & $\mathbf{p ~ ( s e x )}$ \\
\hline Bar & 26.3 & 46.6 & 8.27 & $<0.01$ \\
At home & 19.7 & 13 & 0.42 & 0.51 \\
In dormitory & 32.9 & 13 & 11.79 & $<0.001$ \\
Coffee shop & 7.9 & 5.3 & 0.53 & 0.46 \\
At work & 2.6 & 2.4 & 0.02 & 0.87 \\
At university & 2.6 & 3.8 & 0.20 & 0.64 \\
\hline
\end{tabular}

$n=104$ males, 145 females, $\chi^{2}(1, N=207)$

\section{Effects of consumption on blood pressure and heart rate}

The baseline characteristics of volunteers are listed in Table 8. Originally, five female and seven male volunteers were involved in the study, but complete datasets were obtained only for five participants from each gender. The mean age of the volunteer students was $21.4 \pm 2.31$ years. Nine of them had normal body mass index (BMI), and one was overweight.

Table 8: Study subjects

\begin{tabular}{lc}
\hline Parameters & Volunteer Group \\
\hline Sex Female & 5 \\
$\quad$ Male & 5 \\
Age, years & $21.4 \pm 2.31$ \\
Height (m) & $1.74 \pm 0.075$ \\
Weight (kg) & $70.3 \pm 10.73$ \\
BMI & \\
$>24.9$ & 1 \\
$18.5-24.9$ & 9 \\
$<18.5$ & 0 \\
\hline
\end{tabular}

Table 9 describes the blood pressure (SBP, DBP) and heart rate (HR) parameters observed during the experiment. All parameters were recorded in triplicate before and after energy or control drink consumption. Statistically significant changes were observed in heart rate in the case of the control drink, whereupon 20 minutes after consumption the heart rate declined (Fig. 1). 
The second energy drink (Drink 2) used in the experiment caused statistically significant increase in volunteers' systolic blood pressure (Table 9, Fig. 1).

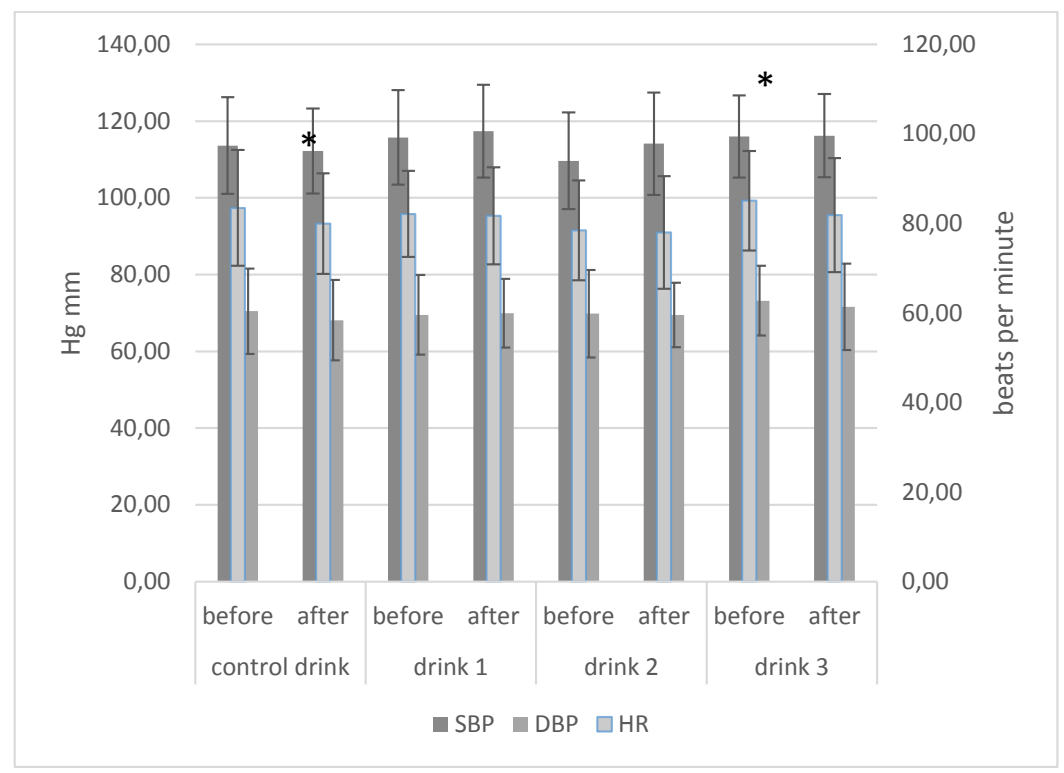

Figure 1: Changes in systolic blood pressure (SBP), diastolic blood pressure $(\mathrm{DBP})$, and heart rate $(\mathrm{HR})$ among participants $(\mathrm{n}=30,10$ volunteers, 3 repeats)

* Significance (at $p<0.05)$ was only stated in the case of HB (decreased) in control drink and in the case of SBP in Drink 2 (increased)

Similarly to our findings, other studies report no significant difference in heart rate after energy drink consumption (Shah et al., 2016; Nowak et al., 2018). In contrast with our data, a significant heart rate decline was observed by Hajsadeghi et al. (2016) in the case of 44 volunteer students from Iran after consuming energy drinks.

Significant increase in systolic blood pressure (SBP) was observed in the case of 38 German students after 1 hour of 750-1000 ml energy drink administration (Basrai et al., 2019) and 34 Canadian volunteers after 30 minutes of $500 \mathrm{ml}$ energy drink consumption (Shah et al., 2019), which is in accordance with our results for Drink 2. No significant changes in systolic blood pressure was observed by Hajsadeghi et al. (2016) and Nowak et al. (2018), whereas the latter study reported a significant increase in diastolic blood pressure after the consumption of three doses of energy drinks. 
Table 9: Blood pressure and heart rate data recorded during the experiment

\begin{tabular}{|c|c|c|c|c|c|c|c|c|c|c|c|c|}
\hline \multirow{2}{*}{ 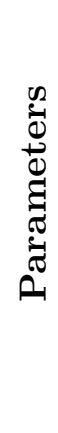 } & \multicolumn{3}{|c|}{$\begin{array}{c}\text { Control drink } \\
(\mathrm{n}=30, \\
10 \text { volunteers, } \\
3 \text { repeats })\end{array}$} & \multicolumn{3}{|c|}{ Drink 1} & \multicolumn{3}{|c|}{ Drink 2} & \multicolumn{2}{|c|}{ Drink } & 3 \\
\hline & 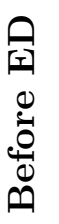 & 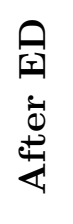 & p & $\begin{array}{l}\text { 国 } \\
0 \\
0 \ddot{0} \\
0 \\
0 \\
0\end{array}$ & 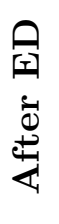 & $\mathbf{p}$ & $\begin{array}{l}\text { 国 } \\
0 \\
0 \\
0 \\
0 \\
0\end{array}$ & 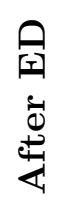 & $\mathbf{p}$ & 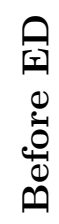 & 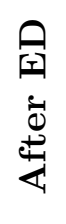 & $\mathbf{p}$ \\
\hline 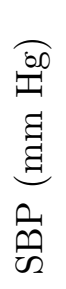 & 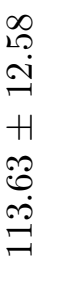 & 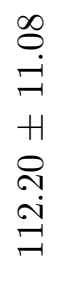 & $\stackrel{\mathscr{H}}{\stackrel{\leftrightarrow}{\leftrightarrow}}$ & 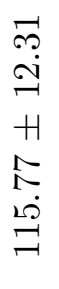 & 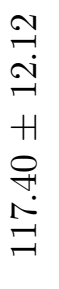 & $\begin{array}{l}\mathscr{2} \\
\stackrel{\sim}{S} \\
\tilde{o}\end{array}$ & 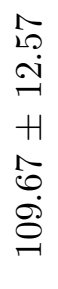 & 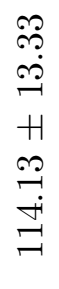 & $\begin{array}{l}\stackrel{2}{O} \\
\dot{0} \\
V\end{array}$ & $\begin{array}{l}\mathfrak{\imath} \\
0 \\
0 \\
H \\
\ddot{0} \\
0 \\
\stackrel{0}{=}\end{array}$ & 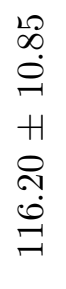 & $\stackrel{\stackrel{ }{\sharp}}{\stackrel{\text { }}{\circ}}$ \\
\hline 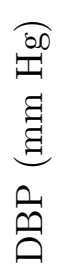 & 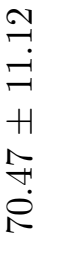 & 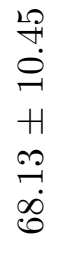 & $\begin{array}{l}\stackrel{\Upsilon}{O} \\
\stackrel{\leftrightarrow}{0} \\
0\end{array}$ & 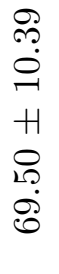 & $\begin{array}{l}\mathscr{Q} \\
\infty \\
\infty \\
H \\
\mathscr{0} \\
\mathscr{0} \\
\mathscr{0}\end{array}$ & $\begin{array}{l}\vec{\infty} \\
0 \\
0 \\
0\end{array}$ & 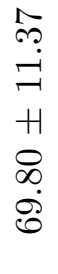 & $\begin{array}{l}\vec{H} \\
\infty \\
H \\
+ \\
\stackrel{\sim}{\not} \\
\dot{0}\end{array}$ & $\begin{array}{l}\stackrel{1}{1} \\
\infty \\
0 \\
0\end{array}$ & 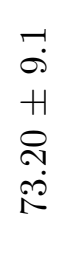 & 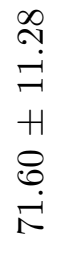 & $\begin{array}{l}\vec{b} \\
\stackrel{0}{0}\end{array}$ \\
\hline 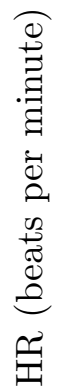 & 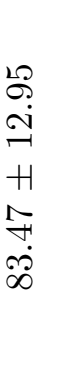 & 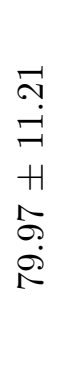 & $\begin{array}{l}\stackrel{2}{O} \\
0 \\
V \\
V\end{array}$ & 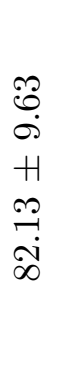 & $\begin{array}{l}\infty \\
\infty \\
0 \\
0 \\
+1 \\
+1 \\
\stackrel{1}{0} \\
\dot{\infty}\end{array}$ & $\stackrel{\stackrel{m}{\perp}}{\ddot{0}}$ & 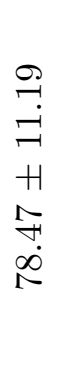 & 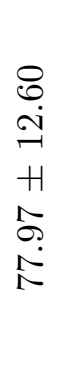 & $\begin{array}{l}-7 \\
0 \\
0\end{array}$ & 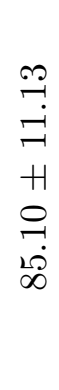 & 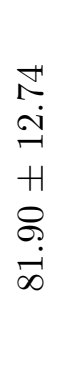 & $\stackrel{\mathscr{g}}{\stackrel{8}{0}}$ \\
\hline
\end{tabular}

Data on both increase and no difference in blood pressure and heart rate were published in the literature, being highly influenced by the amount of energy drink consumed and the timing of measurements after consumption. 


\section{Conclusions}

Energy drinks are popular among the examined faculty students; as shown in our study, $87.1 \%$ of the students consumed ED at least once. Two-thirds of the consumers use one bottle per month - significantly more females, while significantly more males consume ED with daily frequency. Students consume energy drinks mainly for its taste and very rarely to enhance learning efficiency. Differences between the sexes in consumption place preferences were observed: females preferring bars while males dormitories.

We demonstrated the increase in systolic blood pressure (SBP) in young and healthy volunteer students for one type of energy drink. Other changes in blood pressure and heart rate were not observed. Due to the fact that the experiment depends on the type and quantity of energy drinks and exposure time, future investigations are necessary on a larger population.

\section{Acknowledgements}

The authors wish to thank the anonymous students for filling in the questionnaire and the volunteers for their participation in the experiments.

\section{References}

[1] A. A. Alsunni, Energy drink consumption: Beneficial and adverse health effects. International Journal of Health Sciences, 9. 4. (2015) 468-474.

[2] M. Basrai et al., Energy drinks induce acute cardiovascular and metabolic changes pointing to potential risks for young adults: A randomized controlled trial. The Journal of Nutrition, 149. 3. (2019) 441450. DOI: $10.1093 / \mathrm{jn} / \mathrm{nxy} 303$.

[3] S. Benson, B. Tiplady, A. Scholey, Attentional and working memory performance following alcohol and energy drink: A randomised, doubleblind, placebo-controlled, factorial design laboratory study. PLoS ONE, 14. 1. (2019) e0209239. https://doi.org/10.1371/journal.pone.0209239.

[4] A. Bichler, A. Swenson, M. A. Harris, A combination of caffeine and taurine has not effect on short term memory but induces changes in heart rate and mean arterial blood pressure. Amino Acids, 31. (2006) $471-476$. 
[5] B. Bulut, N. E. Beyhun, M. Topbas, G. Çan, Energy drink use in university students and associated factors. Journal of Community Health, 39. 5. (2014) 1004-1011. DOI: 10.1007/s10900-014-9849-3.

[6] Commission Directive 2002/67/EC of 18 July 2002 on the labelling of foodstuffs containing quinine and of foodstuffs containing caffeine.

[7] É. Dojcsákné Kiss-Tóth, E. Kiss-Tóth, Energiaital fogyasztási szokások és egészségtudatosság a felsofokú képzésben résztvevő hallgatók körében [Energy drink consumption habits and health consciousness among higher education students]. Egészségfejlesztés, 59. 4. (2018) 17-26.

[8] K. Friis, J. I. Lyng, M. Lasgaard, F. B. Larsen, Energy drink consumption and the relation to socio-demographic factors and health behaviour among young adults in Denmark. A population-based study. The European Journal of Public Health, 24. 5. (2014) 840-844. DOI: 10.1093/eurpub/cku003.

[9] S. Hajsadeghi et al., Effects of energy drinks on blood pressure, heart rate, and electrocardiographic parameters: An experimental study on healthy young adults. The Anatolian Journal of Cardiology, 16. 2. (2016) 94-99. DOI: 10.5152/akd.2015.5930.

[10] M. Itany et al., Consumption of energy drinks among Lebanese youth: A pilot study on the prevalence and side effects. International Journal of High Risk Behaviors and Addiction, 3. 3. (2014) e18857. DOI: 10.5812/ijhrba.18857.

[11] S. Lee, R. Hudson, K. Kilpatrick, T. E. Graham, R. Ross, Caffeine ingestion is associated with reductions in glucose uptake independent of obesity and type 2 diabetes before and after exercise training. Diabetes Care, 28. 3. (2005) 566-572.

[12] B. M. Malinauskas, V. G. Aeby, R. F. Overton, T. Carpenter-Aeby, K. Barber-Heidal, A survey of energy drink consumption patterns among college students. Nutrition Journal, 6. (2007). DOI: 10.1186/1475-28916-35.

[13] R. McKetin, A. Coen, S. Kaye, A comprehensive review of the effects of mixing caffeinated energy drinks with alcohol. Drug and Alcohol Dependence, 151. (2015) 15-30. DOI: 10.1016/j.drugalcdep.2015.01.047. 
[14] Mordor Intelligence: Energy drinks market - Growth, trends and forecast (2019-2024); home page: https://www.mordorintelligence.com/ industry-reports/energy-drinks-market?gclid=EAIaIQobChMI5f_VqIL M5AIVEKWaCh3ZHQFEEAAYAiAAEgLhxfD_BwE (accessed on: 10. 09.2019).

[15] D. Nowak, M. Goslinski, K. Nowatkowska, The effect of acute consumption of energy drinks on blood pressure, heart rate and blood glucose in the group of young adults. International Journal of Environmental Research and Public Health, 15. (2018) 544. DOI: 10.3390/ijerph15030544.

[16] E. Oprea, L. L. Ruta, I. C. Farcasanu, Pharmacological aspects and health impact of sports and energy drinks. In: A. M. Grumezescu, A. M. Holban (eds.), Sports and energy drinks. Woodhead Publishing (2019) 65-129.

[17] L.A.B. Persad, Energy drinks and the neurophysiological impact of caffeine. Frontiers in Neuroscience, 5. (2011). DOI: 10.3389/fnins.2011. 00116.

[18] M. L. Pettit, K. A. DeBarr, Perceived stress, energy drink consumption and academic performance among college students. Journal of American College Health, 59. 5. (2011) 335-341.

[19] S. Scuri et al., Energy drink consumption: A survey in high school students and associated psychological effects. Journal of Preventive Medicine and Hygiene, 59. (2018) E75-E79.

[20] A. Sema, B. Çakir, Energy drink consumption in college students and associated factors. Nutrition, 27. 3. (2011) 316-322. DOI: 10.1016/j.nut.2010.02.008.

[21] S. A. Shah et al., Impact of acute energy drink consumption on blood pressure parameters. Annals of Pharmacotherapy, 50. 10. (2016) 808815. DOI: $10.1177 / 1060028016656433$.

[22] S. A. Shah et al., Impact of high volume energy drink consumption on electrocardiographic and blood pressure parameters: A randomized trial. Journal of the American Heart Association, 8. 11. (2019). DOI: 10.1161/jaha.118.011318. 
[23] J. Utter, S. Denny, T. Teevale, J. Sheridan, Energy drink consumption among New Zealand adolescents: Associations with mental health, health risk behaviours and body size. Journal of Paediatrics and Child Health, 54. 3. (2017) 279-283. DOI: 10.1111/jpc.13708.

[24] J. C. Verster et al., Alcohol mixed with energy drink (AMED): A critical review and meta-analysis. Human Psychopharmacology: Clinical and Experimental, 33. 2. (2018) e2650. DOI: 10.1002/hup.2650.

[25] V. Vitiello, L. Diolordi, M. Pirrone, L. M. Donini, V. Del Balzo, Energy drink consumption in Italian university students: Food habits and lifestyle. La Clinica Terapeutica, 167. 6. (2016) 175-181.

[26] S. Zucconi et al., Gathering consumption data on specific consumer groups of energy drinks. Supporting Publications, (2013) 1-190. Available online at: www.efsa.europa.eu/publications. 